\title{
Correction to: Transient Liquid Phase Bonding
}

\author{
J. R. Holaday and C. A. Handwerker
}

\section{Correction to:}

Chapter 9 in: K. S. Siow (ed.),

Die-Attach Materials for High Temperature Applications

in Microelectronics Packaging, https://doi.org/10.1007/978-3-319-99256-3_9

The original version of the book was inadvertently published with an incorrect phrase stating "Need more here. Combine with above?" in Page 237 under Section 8.1.3 Au-In. This phrase has been corrected to show "At low temperatures, $\mathrm{Au}-\mathrm{In}$ forms seven IMC phases between Au and In, with AuIn2, AuIn, and Au7In3 observed in the reaction zone between $\mathrm{Au}$ and In even at the shortest reaction times [84]." 